\title{
Effects of Need for Affiliation on Performance and Motivation in Cooperative Table Tennis Instruction
}

\author{
Tseng, Shu-Ping, Chin-Yun Huang \\ Office of Physical Education, Tainan University of Technology, Tainan, Taiwan, R.O.C. \\ Center of Physical Education, Nanhua University, Chia- Yi, Taiwan, R. O. C \\ *pecyh@mail.ncyu.edu.tw
}

\begin{abstract}
The purpose of this study was to investigate the effect of cooperative learning and the motivation on performance and satisfaction from a table tennis teaching perspective. Participants used either a cooperative or individual learning strategy while receiving a video program and instructional information, skill practicing, and feedback from an instructional table tennis lesson. After receiving specific directions for implementing individual versus cooperative strategies, 60 university students, classified as high and low need motivation for affiliation, were randomly assigned to treatments. Students completed a basic table tennis lesson, the effects of cooperative learning and the need motivation for affiliation were examined across posttest. Satisfaction was also assessed. Results revealed that students in the low motivation need for affiliation treatment outperforming those in the high motivation need for affiliation treatment. However, the result did not reveal a significant main effect for instructional method. This finding does not appear to supports the large body of literature from motor skill instruction and traditional learning environments that cooperative learning is superior to individual conditions. Furthermore, the result revealed a significant interaction between instructional method and the motivation need for affiliation, and a significant main effect for instructional method. These data suggest that participants who worked cooperatively reported greater overall satisfaction with the instruction than those who worked individually. The implications for cooperative learning use on the motivational factors for physical education and future research are discussed.
\end{abstract}

Keyword: Need for Affiliation; Cooperative Learning; Motivation; Table Tennis.

\section{INTRODUCTION}

Teachers of physical education commonly present learners with a variety of information that is intended to facilitate learning (Siedentop, 1991). One of the most common techniques employed to achieve this goal is providing instructional interaction. Although there appears to be a consensus among the physical educators in teaching and training that interaction facilitates learning (Gagne, 1985; Dyson, 2014), there are few research based guidelines delving into teaching methods and instructional strategies which enhance depth of processing on motor skill. The role of education is to promote collaboration with others to show the multiple perspectives that can be brought to bear on a particular problem and to arrive at self chosen positions to which they can commit themselves (Merrill, 1991). Meaning is negotiated from multiple perspectives. Conceptual growth comes from the sharing of multiple perspectives and the simultaneous changing of our internal representations in response to those perspectives. Cooperative learning is a critical component of this environment (Dyson, 2005; Yeh, 2011; Johnson \& Johnson, 2009).

Some researchers report that cooperative learning positively affected performance in the instructional lessons (Dyson, 2014; Dyson, \& Casey, 2012; Artut, 2010; Johnson \& Johnson, 2009; Klein and Doran, 1999). Others have not found a significant effect for performance and attitudes when learners used cooperative strategies (Carrier and Sales, 1987). These differences in findings could be due to the types of learners who participated in domain of study. In addition, Researches have reported that student characteristics impact performance and motivation in cooperative studies. Factors such as personality, gender and ability have impacted outcomes in some of the studies. Researchers suggest that individuals' motivational characteristics may influence how they perform in cooperative 
environments (Johnson \& Johnson, 1993; Hooper \& Hannafin, 1991). Using the California Psychological Inventory, Sutter and Reid (1969) found that cooperative learning is better for students with high levels of sociability (i.e., those who are outgoing, sociable, and have a participative temperament), while individual learning condition is better for students who are introverts.

According to Johnson and Johnson (1993), some individuals are more predisposed to act cooperatively; such people prefer cooperative settings over individual settings. The need for an affiliation is represented by a desire to participate in cooperative, noncompetitive activities and by a desire for close, friendly relationships with others (Slavin, 1987). Individuals with a high motivation need for affiliation are more friendly, sociable, and cooperative than those with a low motivation need for affiliation (Jackson, 1974). Motivational design theory suggests that students should be provided with opportunities for cooperative interaction to satisfy the motivation need for affiliation (Keller, 1988).

This present study attempted to examine the effects of cooperative learning and the motivation need for affiliation on motor skill performance and satisfaction. The effects of cooperative learning and motivation need for affiliation were examined across posttest. Satisfaction was also assessed. More specifically, the following questions were addressed in this study: (1) Are there significant differences in the posttest performance between those who participated in cooperative learing and those who participated in individual condition? (2) Are there significant interactions between the motivation need for affiliation and cooperative conditions? (3) Will high affiliation students in the cooperative learning perform significantly better than those in the individual conditions? (4) Do students in cooperative treatment possess better satisfaction toward the instructional module than those in the individual treatment?

\section{Method}

\subsection{Participants}

Participants were 60 volunteer undergraduate students enrolled in required physical education course in table tennis. Participants had the option not to participate or withdraw from the study at anytime. The gender distribution was 31 males and 29 females. Participants were randomly assigned to one of two treatments cooperative or individual learning strategy and were assigned to one of two motivation need for affiliation categories-high or low. Equal numbers of participants were randomly assigned to treatments: 15 Participants in the individual learning/low-affiliation group, 15 in the individual learning/high-affiliation group, 15 in the cooperative learning/low-affiliation group, and 15 in the cooperative learning/high-affiliation group.

\subsection{Materials}

Materials used in this study were an instructional table tennis lesson, a motivation need for affiliation scale, an instrument to measure student satisfaction, and a performance posttest.

The table tennis lesson. The lesson used in the study was designed to help the beginners build their basic skill in table tennis. The goal of this program was that the learner should develop a lucid and sensible approach to basic skill of stroke motion. During the practicing stage, students received immediate feedback in specific skill areas by instructor. This unit is designed for self-instruction and group learning. The content presented in the module consists of four segments: 1) Basic-stroke analysis. 2) Full stroke analysis. 3) Dynamic features analysis. 4) Drill setting (Owens \& Bunker, 1995). In pilot studies, the instructional lesson was reviewed and revised by two content experts and three table tennis instructors. The instructional lesson was formatively evaluated using students of the target group, and was revised into its final form for instructional unite.

The affiliation scale of the Personality Research Form-E. This scale consists of 16 items that measure the degree to which an individual is motivated to affiliate with others. A true/false format is used to indicate whether or not a person agree with statements such as "Sometimes I have to make a real effort to be social" and "I spend lots of time visiting friends." According to Jackson (1974) study, the mean for this scale is $8.6(\mathrm{SD}=3.35)$ and that the internal consistency reliability is .86 when used with college students (Jackson, 1974). For participants in the current study the mean was 10.06 (SD = 3.64), and the range was 1-16. A median split was used to assign participants to high and low 
categories of the motivation need for affiliation. Participants with scores at or above the median (Md $=11)$ were assigned to the high-affiliation category $(n=28)$ and those with scores below the median were assigned to the low-affiliation category $(\mathrm{n}=28)$.

The Instructional Materials Motivation Scale (IMMS). Satisfaction was measured using this scale (Keller, 1988). This scale consists of six questions that measure student perceptions toward the motivational characteristics of instruction in the affective area of satisfaction. A five-point Likert scale is used to answer the questions. The Cronbach alpha internal-consistency relationship reliability estimate of this scale is .92 (Keller, 1988).

Posttest. Tenth weeks after completing the instruction and practicing, all students received a skill of performance posttest. This posttest unit was adapted according to the standard text (Owens and Bunker, 1995). The posttest was based on skill application of learning outcomes to test students' ability on the accuracy skills during the game. Data from the pilot studies were used to determine reliability estimates for posttest. Cronbach's alpha method was used to calculate the reliability of the posttest, and was found to have a value of .86 .

\subsection{Procedures}

The study was implemented during a ten-week period. The pretest was administered during the first week. The study consisted of seven 30-minute periods instructional model units. In addition, each group was given seven 60-minutes periods on skill practicing during the two to ninth week. Participants were randomly assigned to one of two treatment conditions, one which required subjects to work individually during the lesson and one which required subjects to work in triads.

Participants received specific directions for implementing individual versus cooperative strategies. Participants who would be working alone were given a direction, instructed to work independently during the lesson, and told to do their best work. Participants who would be working in triads were randomly assigned in the group. Each triad was given a worksheet and told to work together and discuss the given feedback during the lesson. The purpose of the directions was given to the cooperative learning group's instructors to help reinforce those behaviors students need in order to work cooperatively. The study was conducted in the table tennis room for instruction and skill practicing in the university setting. Upon completion the ninth week of the lesson, each participant individually completed the affiliation scale and the satisfaction questionnaire. The posttest was delivered in the final week of the study.

\subsection{Experimental Design and Analysis}

A 2 x 2 factorial design was used, with instructional method-individual or cooperative and motivation need for affiliation-high or low as the independent variables. The dependent variables were performance and satisfaction. Analysis of variance (ANOVA) was used to test for an overall difference between groups on the posttest and satisfaction scale. This analysis was also followed by univariate analyses on the individual satisfaction items. Analyses were performed on all dependent measures, using Statistical Package for the Social Sciences (SPSS) 12.0 version. The alpha level chosen for statistical significance was .05. Both descriptive and inferential analyses were performed on the data collected for the study.

\section{RESUlts}

\subsection{Performance}

The first dependent variable of the study was student performance. This variable was operationally defined as an individual's score on the posttest. Means and standard deviations of student performance on posttest are given in Table 1. The results of the ANOVA showed significant main effects for the motivation need for affiliation $\mathrm{F}(1,56)=4.15$, $\mathrm{p}<.05$, A simple inspection of the means shows students in the low motivation need for affiliation treatment $(M=16.80)$ outperforming those in the high motivation need for affiliation treatment $(M=14.60)$. However, the ANOVA did not reveal a significant main effect for instructional method.

ANOVA revealed a significant interaction between instructional method and the motivation need for affiliation, $\mathrm{F}(1,56)=3.52, \mathrm{p}<.05$. This analysis indicated that performance of participants with a high motivation need for affiliation who worked alone was significantly lower than that of all other groups on the posttest. 


\subsection{Satisfaction}

Satisfaction was measured using the Instructional Materials Motivation Scale Subscale S (Keller, 1987). Mean scores and standard deviations for each item on the satisfaction measure was given table 2. ANOVA revealed a significant interaction between instructional method and the motivation need for affiliation, $\mathrm{F}(1,56)=2.86, \mathrm{p}<.05$, and a significant main effect for instructional method, $\mathrm{F}(1,56)=$ $2.54, \mathrm{p}<.05$. These data suggest that participants who worked cooperatively reported greater overall satisfaction with the instruction. $(\mathrm{M}=16.55, \mathrm{SD}=4.70)$ than those who worked individually $(\mathrm{M}=$ $13.49, \mathrm{SD}=3.44)$. Univariate analyses revealed that the interaction was not significant for any of the individual satisfaction items.

Table1. Means and Standard Deviations on Performance Posttest and Satisfaction

\begin{tabular}{|l|l|l|l|l|}
\hline Condition & \multicolumn{2}{l|}{ Performance Posttest } & \multicolumn{2}{l|}{ Satisfaction } \\
\hline & M & SD & M & SD \\
\hline Cooperative & & & & \\
\hline High Affiliation $(\mathrm{n}=15)$ & 15.70 & 1.06 & 16.78 & 4.74 \\
\hline Low Affiliation $(\mathrm{n}=15)$ & 15.75 & 1.48 & 16.23 & 4.68 \\
\hline Total $(\mathrm{n}=30)$ & 15.73 & 1.27 & 16.55 & 4.70 \\
\hline Individual & & & & \\
\hline High Affiliation $(\mathrm{n}=15)$ & 14.60 & 1.26 & 14.45 & 4.24 \\
\hline Low Affiliation $(\mathrm{n}=15)$ & 16.80 & 1.80 & 12.53 & 2.68 \\
\hline Total $(\mathrm{n}=30)$ & 15.78 & 1.53 & 13.49 & 3.44 \\
\hline
\end{tabular}

Table2. Means and Standard Deviations for Satisfaction items

\begin{tabular}{|c|c|c|c|c|c|c|}
\hline & \multicolumn{6}{|c|}{ Group } \\
\hline & \multicolumn{2}{|c|}{ Cooperative } & \multicolumn{2}{|c|}{ Individual } & \multicolumn{2}{|l|}{ Total } \\
\hline Scale Item & M & SD & M & SD & M & SD \\
\hline 1. Participation was satisfying & 3.85 & 0.93 & 2.23 & 0.97 & 3.04 & 0.96 \\
\hline 2. Practice and feedback were satisfying & 3.68 & 1.07 & 2.78 & 1.26 & 3.23 & 1.18 \\
\hline 3. Would like to participate in similar activity & 3.82 & 1.84 & 1.72 & 0.87 & 2.77 & 1.15 \\
\hline 4. Did not enjoy activity & 2.98 & 1.48 & 3.75 & 1.08 & 3.36 & 1.34 \\
\hline 5. Felt good to complete activity successfully & 3.32 & 1.22 & 2.67 & 1.26 & 2.99 & 1.30 \\
\hline 6. Activity was well designed & 3.96 & 1.08 & 2.75 & 1.18 & 3.35 & 1.18 \\
\hline
\end{tabular}

\section{DISCUSSION}

The purpose of this study was to investigate the effect of cooperative learning and the motivation need for affiliation on performance and satisfaction. Participants used either a cooperative or individual learning strategy while receiving a program and instructional information, skill practicing, and feedback from an instructional table tennis lesson. ,In this study, the effects of cooperative learning and the motivation need for affiliation were examined across posttest. Satisfaction were also assessed.

The results of this study revealed that there was no difference between the two groups when performance was measured. This finding does not appear to supports the large body of literature from motor skill instruction and traditional learning environments (Grineski, 1996; Johnson, Bjorkland and Krotee, 1984; Johnson and Johnson, 1993). That cooperative learning is superior to individual conditions. However, performance results revealed an interaction between instructional method and the motivation need for affiliation. When participants were asked to apply what they learned, performance of participants with a high motivation need for affiliation who worked alone was lower than that of all other groups.

One possible reason for this finding is that putting students into groups to learn is not the same thing as structuring cooperative among students. The basic cooperative skills training was required to guide students toward better use of cooperative behaviors (Johnson and Johnson, 1993). Another possible explanation for this result is that people with a high motivation need for affiliation are less likely than those with a low motivation need for affiliation to be motivated and to learn when instruction is presented via table tennis program. Students with a high affiliation motive prefer to participate in activities that allow them to work with others. Hence, students with a high motivation need for 
affiliation should be given the opportunity to interact with others when instruction is motor skill domain.

Another finding of the present study revealed that participants who worked cooperatively reported greater overall satisfaction with the instruction. One plausible explanation for the results obtained is that students in groups feel more supported and satisfied than other students. They may also feel privileged because their high ability partners are always available to help them. According to Johnson \& Johnson (1993), for college and adult studies, interaction improves interpersonal attraction when the interaction helps individuals to achieve personal goals.

Some potential limitations of this study should be noted. The relatively short duration of the treatment and the effect of instructional control may have influenced the outcomes. Extending the experimental time for overall instruction could produce different results for satisfaction and performance.

More researches should be conducted to examine the effects of varieties of qualitative measures may provide better insights than quantitative measures in analyzing peer interaction in small cooperative groups. Further research should identify critical conditions under which effective peer interaction can be generated and maintained on the domain of motor skill training setting.

\section{REFERENCES}

Artut, P. D. (2010). Experimental evaluation of the effectives of cooperative learning on kindergarten children's mathematics ability. International Journal of Educational Research, 48, 370-380.

Dyson, B. (2014). Cooperative Learning: Cooperative Learning as a Transformative Pedagogy in Physical Education Cultura, Ciencia y Deporte, vol. 9, núm. 26, mayo-agosto, 2014, pp. 93-94. Universidad Católica San Antonio de Murcia, España

Dyson, B. (2005). Integration cooperative learning and tactical games models: Focus on social interactions and decision-making. In J. I. Bulter and L. L. Griffin (Eds.), Teaching games for understanding: Theory, research, and practive (pp. 149-168). Champaign, IL: Human Kinetics.

Dyson, B., \& Casey, A. (Eds.). (2012). Cooperative learning in physical education: a research based approach. Routledge.

Grineski, S. (1996). Cooperative learning in physical education. Human Kinetics, Champain, IL.

Gagne, R. M. (1985). The conditions of learning. $4^{\text {th }}$ Ed. NY: Holt, Rinehart, and Winston.

Hooper, S., \& Hannafin, M. J. (1991). The effects of group composition on achievement, interaction, and learning efficiency during computer-based cooperative instruction. Educational Technology Research and Development, 39(3), 27-40.

Jackson, D. N. (1974). Personality research form manual, Goshen, NY: Research Psychologist Press.

Johnson, D. W., \& Johnson, R. T. (2009). An educational psychology success story: Social interdependence theory and cooperative learning. Educational researcher, 38(5), 365-379.

Johnson, D. W., \& Johnson, R. T. (1993). Cooperative learning and feedback in technology-based instruction. In Dempsey, J., \& Sales, G. C. (Ed.). Interactive_instruction and feedback. Englewood Cliffs NJ: Educational Technology Publications.

Johnson, D. W., Bjorkland, R.,\& Krotee, M. (1984). The effects of cooperative, competitive, and individualistic student interaction patters on the achievement and attitudes of students learning the golf skill of putting. Research of Quarterly, 55, 129-134.

Keller, J. M. (1987). Instructional materials motivation scale (IMMS). Unpublished manuscript, Florida State University, Tallahassee.

Klein, J. D, \& Doran, M. S. (1999). Implementing individual and small group learning structures a computer simulation. Educational Technology Research and Development, 47(1), 97-110.

Merrill, M. D. (1991). Constructivism and Instructional design. Educational Technology, 31(2), 45-53.

Owens, D. \& Bunker, L. K. (1995). Table tennis: Steps to Success. Human Kinetics Publishers, Inc. Champaign, IL.

Siedentop, D. (1991). Developing teaching skills in physical education (3rd Ed.). Palo Alto, CA: Mayfield.

Singhanayok, C, \& Hooper, S. (1998). The effects of cooperative learning and learner control on 
students' achievement, option selections, and attitudes. Educational Technology Research and Development, 46(2), 17-33.

Slavin, R. E. (1987). Cooperative learning: where behavioral and humanistic approaches to classroom motivation meet. Elementary School Journal, 88(1), 29-37.

Yeh, S. F. (2011). Peer interaction feedback and cooperative learning on performance and motivation during wood ball instruction. Journal of Physical Education in Taiwan, 44(1), 93-104.

\section{AUTHORS' BIOGRAPHY}

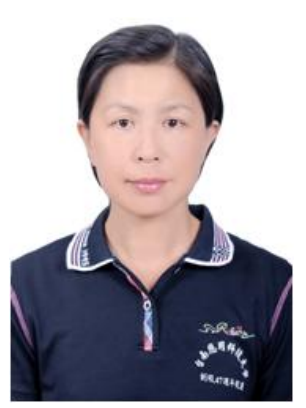

Shu-Ping Tseng, is the instructor of yoga, physical fitness, and table tennis at Tainan University of Technology. Her experties is archery and she once played for the national team in Taiwan.

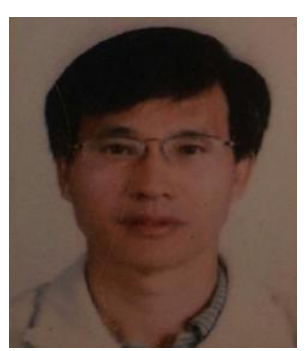

Chin-Yun Huang, received his Ph.D. in Instructional Technology from University of Minnesota. He currently teaches at Nanhun University. His experties is sport pedagogy and instructional system design. 